IRA-International Journal of Management \& Social Sciences

ISSN 2455-2267; Vol.03, Issue 03 (2016)

Institute of Research Advances

http://research-advances.org/index.php/RAJMSS

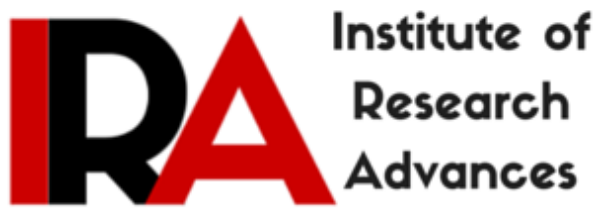

\title{
Stock Return Autocorrelation and Volatility in Emerging Nations
}

\author{
${ }^{1}$ Tarika Singh \\ Prestige Institute of Management, Gwalior, India. \\ ${ }^{2}$ Seema Mehta \\ Indian Institute of Health Research and Management, Jaipur, India. \\ ${ }^{3}$ Abhijeet Saban, ${ }^{4}$ Sparshi Garg \& ${ }^{5}$ Divya Pamnani \\ Prestige Institute of Management, Gwalior, India.
}

DOI: http://dx.doi.org/10.21013/jmss.v3.n3.p25

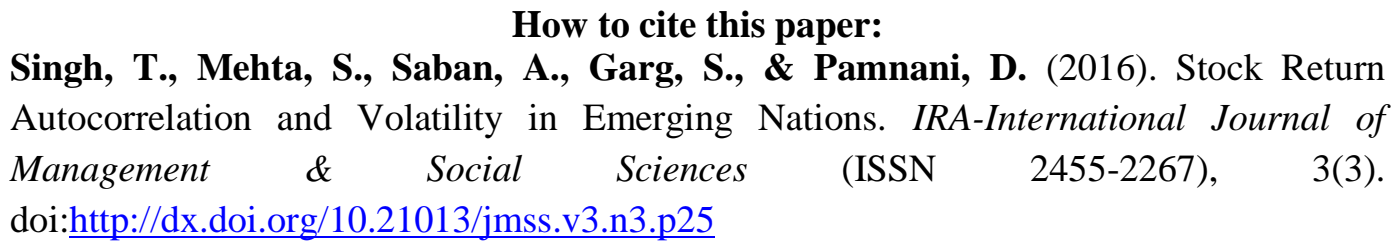

(C) Institute of Research Advances

(cc) BY-NC

This works is licensed under a Creative Commons Attribution-Non Commercial 4.0 International License subject to proper citation to the publication source of the work.

Disclaimer: The scholarly papers as reviewed and published by the Institute of Research Advances (IRA) are the views and opinions of their respective authors and are not the views or opinions of the IRA. The IRA disclaims of any harm or loss caused due to the published content to any party. 


\begin{abstract}
This research has been conducted to estimate the Value at Risk of nations and volatility of returns of indices by using GARCH based models in the emerging equity markets of the world.

For the study six emerging markets were taken into consideration viz. china, India, turkey, Mexico, Indonesia, Russia, and Brazil. The data these emerging stock indices of the world have been taken for the research purpose. Different GARCH (auto regressive) based models were applied to estimate the volatility in markets, further different Garch based models were compared for best fit and VaR was calculated to estimate the risk. The results of Garch $(1,1)$ model shows that there is no serial correlation in Brazil and Mexico and for India, China, Russia and Turkey there exist positive serial correlation. E-garch which is superior model than garch reported that there is no serial correlation in Brazil, china, Mexico and Russia but for India and Turkey there exist positive serial correlation. Further a stronger garch model that is Pgarch was applied which showed that there is positive serial correlation in all the Emerging equity markets viz. India, China, Russia and Turkey. The generalized results can be of positive correlation between India, China, Russia and Turkey markets.
\end{abstract}

Keywords: Volatility, Risk Estimation, Garch Based estimation, Emerging Nation, Autocorrelation

\title{
1.0 Introduction
}

The paper comprises of detailed understanding of GARCH models viz. IGARCH, EGARCH, FIEGARCH and GARCH (p, q) model. The GARCH estimation was used for estimating volatility and $\mathrm{VaR}$ estimation for measuring risk of investment in these nations. This research was conducted to estimate the VAR by using different GARCH based models. The following section shows the understanding of VAR and different GARCH based models used in our study.

\section{Value-At-Risk}

Choudhry (2001) described in his book VaR as a measure of market risk. It is the maximum loss which can occur with set percentage confidence over a holding period of $\mathrm{n}$ days. It is the measure of probability of risk present in the portfolio i.e. the expected loss in the portfolio. It was introduced in October1994 when JP Morgan launched RiskMetrics. The VAR may be calculated in number of ways, using a statistical model or by computer simulation. $\mathrm{VaR}$ is calculated within a given confidence interval, typically $95 \%$ or $99 \%$; it seeks to measure the possible losses from a position or portfolio under "normal" circumstances.

The most commonly used VaR models assume that the prices of assets in the financial markets follow a normal distribution. To implement VaR, all of a firm's positions data must be gathered into one centralized database. Once this is complete the overall risk has to be calculated by aggregating the risks from individual instruments across the entire portfolio. The potential move in each instrument (that is, each risk factor) has to be inferred from past daily price movements over a given observation period. Hence the data on which VaR estimates are based should capture all relevant daily market moves over the previous year. The VAR estimation captures only those risks which can be measured in quantitative terms. 


\subsection{Literature Review}

Koksal and Orhan (2012) studied about the market risk of both developed and developing countries during the global financial crises. The results indicated that the performance of $\mathrm{VaR}$ as a measure of risk is better in developing nations than in developed nations and the possible reason could be deeper impact of global financial crisis on developed countries than emerging markets.

Azizan et al. (2012) forecasted in his study portfolio risk estimation by using GARCH and Var Methods because portfolio risk management is part of their decision-making process. According to Hull (2006), VaR is widely used by fund managers "to provide a single number summarizing the total risk in a portfolio of financial assets." Based on this assumption they conducted an analysis to compare the effectiveness of $\mathrm{VaR}$ analysis and GARCH method in forecasting risk estimation. The results indicated that $\mathrm{VaR}$ is considered better in predicting the risk as it gives the percentage and rank of risk level.

Singh, Allen and Powell (2011) estimated Value at Risk Using Extreme Value Theory. They demonstrated that EVT can be successfully applied to Australian stock market return series for the purpose of predicting next day VaR by using GARCH $(1,1)$ based dynamic EVT approach. They also showed that with back testing results EVT method performed better than GARCH $(1,1)$ and Risk Metrics based forecasts.

Oskooe and Shamsavari (2011) provided results indicating there is no asymmetric effect in the changing volatility. The results also showed that the empirical results from estimating asymmetric GARCH models (TARCH, EGARCH and PARCH) do not confirm the asymmetric volatility in Iran stock market.

Kourouma et al. (2011) estimated in his paper Extreme Value at Risk and Expected Shortfall during Financial Crisis. They took the data of CAC 40, S\&P 500, Wheat and Crude Oil indexes during the 2008 financial crisis. They have shown an underestimation of the risk of loss for the unconditional VaR models as compared with the conditional models. This underestimation is stronger using the historical $\mathrm{VaR}$ approach than when using the extreme values theory VaR model. Even in 2008 financial crisis, the conditional EVT model was more accurate and reliable for predicting the asset risk losses.

Ünal (2011) evaluated in his study Value-at-risk forecasts. In his paper he has compared the performance of various value-at-risks (VaR) forecast models viz. historical simulation, Risk Metrics and models based on extreme value theory.

McMillan and Thupayagale (2010) evaluated Stock Index Return Value-at-Risk Estimates in South Africa by taking in account broader selection of GARCH-based models, which includes a variety of asymmetric and long memory models. The results suggest that models having both asymmetric and long memory attributes surpass other methods in estimating $\mathrm{VaR}$ which are similar to the volatility forecasting.

Dimitris et al. (2010) assessed Value at risk models for volatile emerging markets equity portfolios. The results indicated that although there were documented 
differences between emerging and developed markets, VaR models are more successful and common for both.

McAleer and Oxley (2010) reviewed in his paper robust risk management strategy to the Global Financial Crisis (GFC) to estimate Value-at-Risk (VaR) forecast. The paper further provided evidence on the suitability of the median as a GFC-robust strategy by the use of additional set of new extreme value forecasting models which do not include DPOT and Conditional EVT.

Gnamassou (2010) evaluated in his paper Value-at-risk prediction to compare alternative techniques applied to a large sample of individual stock data. The results show that Historical Simulation, Risk-Metrics, GARCH and GJR-GARCH-based models techniques showed poor performance except when used with Student distribution.

Andjeli , Djaković and Radišić (2010) reviewed in his paper Application of VaR in emerging markets. They investigated the relative performance of Value at Risk (VaR) methods with the daily returns series of four different emerging markets viz Slovenian (SBI20), Croatian (CROBEX), Serbian (BELEX line) and Hungarian (BUX) stock indices. They conducted this research to determine the possibility of application of the HS and Delta normal VaR with $95 \%$ and $99 \%$ confidence level in investment processes on the emerging markets of the selected Central and Eastern European countries. Analyses, synthesis and statistical/mathematical methods were applied. The results indicated that methods shown to afford accurate VaR estimates in developed markets do not necessarily have application on the emerging markets.

Thupayagale (2010) applied GARCH-based models in value-at-risk estimation by forecasting performance of a range of volatility models by using stock index return of emerging markets in context of the basel regulatory framework in Value-at-Risk estimation. Their results suggested that models with long term effects are important in providing improved $\mathrm{VaR}$ estimates that minimise occasions when the minimum capital requirement identified would have fallen short of actual trading losses. Along with that, the results highlighted the relevance Basel regulatory framework, and using out-of-sample forecast evaluation methods for identifying forecasting models that provide accurate VaR estimates.

Ergen (2010) studied in his paper VaR Prediction for Emerging Stock Markets. he took the stock index data of long time series by comparing the performance of ten different market risk models of 12 emerging market by predicting one day ahead Value-at-Risk and back testing these predictions. He uses two-step estimation in his study, which ensures unbiased parameter estimates for the GARCH process. He has also implemented classical single step joint estimation which shows that the twostep methodology provides better backtesting performance.

Xiao and Koenker (2009) estimated conditional quantile for GARCH models by using quantile regression because it is very nonlinear. They have studied asymptotic properties of the sieve approximation, the minimum distance estimators, and the nalquantile regression estimators employing generated regressors. They also used Monte Carlo and empirical application which resulted that the proposed estimation methods perform better than some existing conditional quantile estimation methods. 
Roy (2009) estimated the Value at Risk for the Indian capital market. He took the data of Indian capital market (BSE-SENSEX and NSE-NIFTY) with other global indicators and its own volatility using daily returns covering the period 2003 to 2009. The paper estimates VaR of return in the Indian capital market on the basis of two composite methods i.e. (a) using univariate GARCH and (b) using ARMA for mean equation. The results indicated that after comparison it was found that $\mathrm{VaR}$ of return in the Indian capital market estimated based on GARCH with suitable mean specification performs better than the ARMA-GARCH method.

Kang and Yoon (2009) examined value-at-risk (VaR) analysis performance in the Context of the market volatility of five Asian emerging stock markets. They found that the skewed Student's t APARCH model is the best for incorporating the skewness and excess kurtosis of stock returns, and the appropriate assumption of return distribution can provide more accurate $\mathrm{VaR}$ models. Which helps portfolio managers of trading positions in Asian stock markets can build optimal margin levels.

Carchano et al. (2009) forecasted VaR in Spot and Futures Equity Markets in his research. They took the data of three stock indices - S\&P 500, DAX 30, and Nikkei 225 - for the period December 14, 2004 to December 31, 2008 and presented evidence for the validity of the ARMA-GARCH model with tempered stable innovations to estimate one-day-ahead VaR in the cash and futures markets of the same. They also tested whether adding trading volume to the classical tempered stable model improves the forecasting ability of the model. And finally they also compared the number of times the market data drop below the corresponding oneday-ahead VaR estimations for both spot and futures equity markets in CTS with and without models including trading volume.

Žiković and Aktan (2009) investigated in their paper Global financial crisis and VaR performance in emerging markets. They analyzed relative performance of a wide array of Value at Risk (VaR) models with the daily returns of Turkish (XU100) and Croatian (CROBEX) stock index prior to and during the ongoing financial crisis. Along with this they also studied the behaviour of conditional and unconditional extreme value theory (EVT) and hybrid historical simulation (HHS) models to generate 95, 99 and $99.5 \%$ confidence level estimates. The results showed that at the time of crises all tested VaR model except EVT and HHS models seriously under predict the true level of risk, with EVT mode doing so at a higher cost of capital compared to HHS model.

Kasman (2009) estimated in his paper Value-at-Risk for the Turkish Stock Index Futures by using the $\operatorname{FIGARCH}(1, \mathrm{~d}, 1)$ model with three different distributions: Normal, Student-t, and skewed Student-t. The results indicated that the evidence of long memory in volatility shows uncertainty or risk is an important determinant of the behaviour of daily futures prices in the Turkish futures market. Further empirical results showed that based on the Kupiec LR failure rate test the FIGARCH $(1, d, 1)$ models with skewed Student-t distribution perform better than the results generated by normal distribution.

Altăr and Iorgulescu (2008) analyzed in their paper Value at Risk measure for a portfolio consisting of three stocks traded at Bucharest Stock Exchange by using different model viz. historical volatility, EWMA volatility model, and GARCH type 
models for the volatility of the stocks and of the portfolio and a dynamic conditional correlation (DCC) model. The result indicated that using conditional volatility models and distributional tools which accounts for the non-normality of the returns leads to a better VaR-based risk management. VaR computed on the basis of a GARCH $(1,1)$ model for the volatility of the portfolio returns seems to be the best compromise between precision, capital coverage levels and the required amount of calculations.

Janak and Sarat (2008) investigated the financial integration of India's stock market with that of global and major regional markets. They have used six stock price indices i.e. the 200-scrip index of BSE of India to represent domestic market, stock price indices of Singapore and Hong Kong to represent the regional markets and three stock price indices of U.S., U.K. and Japan to represent the global markets. Based on daily as well as weekly data covering end-March 2003 to end- January 2008 they found that Indian market's dependence on global markets, such as U.S. and U.K., was substantially higher than on regional markets such as Singapore and Hong Kong, while Japanese market had weak influence on Indian market.

Floros (2008) modelled Volatility using GARCH Models. He took the daily data from Egypt (CMA General Index) and Israel (TASE-100 index). He applied various time series methods, including the simple, exponential, threshold, asymmetric component, the component and the power GARCH model. The results indicated that increased risk will not mandatorily lead to a rise in the returns. It was also found that the most volatile series is CMA index from Egypt, because of the uncertainty in prices.

Morimoto (2008) estimated VaR by comparing GARCH models. The comparison was made to evaluate the applicability of such models by using high resolution intraday data for analysing intraday risk. Using transformation data they determined one step ahead VaR and the performance of five multivariate GARCH models were compared on the basis of frequency that the estimated VaR exceeded observed data. It was thus found that for risk management in intraday framework the existing GARCH model could be applied by simply transforming the irregularity spaced data into regular time series. As per the results the dynamic conditional correlation model was considered favourable for risk management.

Benavides and México (2007) analysed in their paper GARCH Processes and Value at Risk for Mexican Interest Rates Futures. Their analysis was carried out for several time-horizons, which has trading at the Mexican Derivatives Exchange. The GARCH process was applied to determine the VaR with time horizons of more than one trading day Real-World Densities (RWD). As per the results GARCH models are relatively accurate for time horizons of one trading day. But the volatility diligence captured by these models is reflected with relatively high VaR estimates for longer time horizons. These results have also implications for short-term interest rate forecasts given that RWD are estimated.

Mike and Philip (2006) conducted the Empirical analysis of GARCH models in estimating VAR by using several GARCH models which included risk metrics and two long memory GARCH models of both long and short positions. They took the data of 12 market indices and four foreign exchange rates. As per their results that both stationary and fractionally integrated GARCH models performed better than 
Risk Metrics in estimating $1 \% \mathrm{VaR}$. The results also indicated that taking a fat-tailed error model for estimating VAR is important. It was found that the t-error models are better than normal-error models in long position. No such asymmetry was observed in the exchange rate data.

Dimitris et al. (2006) estimated VAR for long and short trading positions of Athens Stock Exchange and three stocks exchange of Greek companies which are listed in ASE. Their paper provides estimates of various models of ARCH which are based on skewed student distribution. The results lead to the conclusion that the skewed Student APARCH model performs better than all other requirement modelling VAR for long or short positions.

Assaf (2006) reviewed in his paper extreme Observations in the MENA Stock Markets and Their Implication for VaR measures. In the paper they have used the extreme value theory to analyze four emerging financial markets which belongs to MEENA region including Egypt, Jordan, Morocco, and Turkey. They found that the $\mathrm{VaR}$ estimates based on the tail-index were higher than those based on a normal distribution for all markets, and thus proper risk assessment should not neglect the tail behaviour in these markets, as that can lead to an improper evaluation of market risk.

Rampersad and Watson (2005) studied the efficacy of Value at Risk models in Caribbean Equity Markets and also make recommendations on how existing VaR models may be enhanced to increase their usefulness within the Caribbean context. Their results provides evidence that the most effective VaR models is the parametric $\mathrm{VaR}$ in equity markets.it also indicated that these VaR models utilizing the assumption of time varying volatility were more effective in the Jamaica and Trinidad \& Tobago equity markets than in the Barbados and Eastern Caribbean equity markets.

Kuester et al. (2005) predicted the Value-at-Risk for Comparing Alternative Strategies. For predicting value at risk they have compared the out-of-sample performance of existing methods and some new models by taking 30 years data of NASDAQ. The results indicated that most approaches perform inadequately, except a hybrid method, combining a heavy-tailed GARCH filter with an extreme value theory-based approach which performed best overall.

Eksi, Irem and Kasirg .(2005) applied several tests to test a variety of VaR models. Their results indicated that EVT is theoretically more appropriate for calculating risk measures. Also all other models were found equivalent according to Lopez backtest results whereas EVT is found to be superior to GARCH model according to another test named Kupiec test.

Rombouts and Verbeek (2004) evaluated Portfolio Value-at-Risk using SemiParametric GARCH Models. They estimated various alternative multivariate GARCH models for daily returns on the S\&P 500 and NASDAQ indexes. They also examined the economic value of multivariate GARCH models. The results indicated that the semi parametric models performed uniformly while parametric models gave unacceptable failure rates. It was also found that the semi parametric models are superior and robust. 
Bao et al. (2004) compared the predictive power of alternative VaR models in terms of the empirical coverage probability and the predictive quantile loss for the stock markets of five Asian economies. There results showed that Risk metrics model behaves reasonably well before and after the crisis, except some EVT models which behave better in the crisis period. There experiment also demonstrated that risk forecasting during the crisis period is more difficult and yields poorer results than during still periods.

Fabozzi, Tunaru and Wu (2004) modelled Volatility for the Chinese Equity Markets. They took a wide series of GARCH models for investigating the volatility of the Chinese equity data from the Shenzhen and Shanghai markets. In contrary to previous studies they had found empirical evidence of volatility clustering. Each market containing several GARCH models were used to test spill-over effect between the two Chinese markets. Their results suggested that there is no volatility transmission between the two markets.

Gencay and Selcuk (2004) estimated in their paper the relative performance of the nine emerging markets by using Extreme value theory and Value-at-Risk. They concluded that the risk and reward are not equally similar in given economies.

Angelidis et al. (2003) took perfectly diversified portfolios of five stock indices and evaluated the performance of an extensive family of ARCH models in modelling daily Value- at- Risk (VaR), using a number of distributional assumptions and sample sizes. They found that leptokurtic distributions are able to produce better one-step-ahead VaR forecasts and for the accuracy of the forecast the choice of sample size is very important, whereas the specification of the conditional mean is indifferent.

Fernandez (2003) used a sample comprised of the United States, Europe, Asia, and Latin America. Their findings suggested that (i) on an average; EVT gives the most accurate estimates of value at risk. (ii), tail dependence decreases when filtering out heteroscedasticity and serial correlation by multivariate GARCH models.

Chen, Hae and Hsieh (2003) forecasted Value at Risk (VAR) in the futures market using Hybrid method of Neural Networks and GARCH model. They took the data of NASDAQ 100 and Dow Jones futures index market. The results indicated that the hybrid method has outperformed the conventional method in estimating VAR. it was among all other methods the hybrid method was considered to be the best.

Burns (2002) took the long history of S\&P 500 to compare these estimators with several other common approaches to value at risk estimation. The derived results shown that among all other methods GARCH estimates are in terms of the accuracy and consistency of the probability level. He found that weighting recent observations when fitting the GARCH model was beneficial.

Tagliafichi (2002) applied in his paper the Arch models in the selection of as best Portfolio. It was found that the presence of GARCH effects in the model used for calculating the values of Beta, permit to enforce the idea of obtaining a best coefficients, with minimum variance. 
Chan et al. (2001) used two methods namely the normal approximation and the data tilting method, for the purpose of constructing confidence intervals for the conditional VaR estimator and to assess their accuracies by applying simulation studies. They also applied the proposed approach to an energy market data set. The results indicated that Monte Carlo simulation if studied with the GARCH models along with Student-t innovations will yield valid confidence intervals for the VaR estimator whereas the normal approximation has a slightly higher coverage probability.

Berkowitz and Brien (2001) measured the accuracy of VaR models in commercial banks. They provided descriptive statistics on the trading revenues and the associated Value-at-Risk forecasts internally estimated by banks. For a sample of large bank holding companies, they evaluated the performance of banks' trading risk models by examining the statistical accuracy of the VaR forecasts. This article was the first to provide a detailed analysis of the performance of models actually in use.

Giot and Laurent (2001) modelled in this paper daily value-at-risk using realized volatility and arch type models. They took the data of CAC40 and SP500 for their study. This paper also indicated that daily returns standardized by the square root of the one-day-ahead forecast of the daily realized volatility are not normally distributed.

Danielsson and De Vries (2000) proposed a semi-parametric method for unconditional Value-at-Risk (VaR) evaluation. In which largest risks are modelled parametrically and smaller risks are captured by the non-parametric empirical distribution function. The resulted depicted that at the $5 \%$ level the Risk Metrics analysis is best, but for predictions of low probability, it strongly under predicts the VaR while the semi-parametric method is the most accurate.

Aggarval et al. (1999) analyzed in their paper in Emerging Stock Markets in which cause of major shifts in emerging markets' volatility. The analysis of risk was based on volatility models. They found that there are dissimilar developed markets and large changes in volatility appear to be related to country-specific events.

Mecagni and Sourial (1999) examined in their paper the behaviour of stock returns in the Egyptian stock exchange, pricing securities efficiency, and the relationship of returns and conditional volatility. They used GARCH (p,q)-M models to estimate the daily indices indicating significant departures from the efficient market hypothesis. The results also showed a significant positive link between risk and returns, which thereby significantly affected during the market downturn.

Goorbergh and Vlaar (1999) analyzed the Value-at-Risk Analysis of Stock Returns in his paper by applying various Value-at-Risk techniques to the Dutch stock market index. The main conclusions of the research are: (1) while modelling value-at-risk changing volatility is the most important characteristic of stock returns and this can be modelled by means of GAARCH; (2) By using t-distribution the fat tails of the distribution can be modelled for low confidence levels; (3) Due to not coping up with the volatility clustering phenomenon the tail index estimators are not up to the mark. 
Bekaert and Harvey (1997) analyzed emerging equity market volatility. They showed that the volatilities are significantly negatively correlated, with each market's volatility Granger causing volatility on the other market. International investors can therefore diversify better their portfolios by including such emerging markets. The benefit of diversification on emerging markets is also extensively discussed by them.

Alexendar and Lieh (1997) they examined the performance of the forecasting methods viz. equally weighted average, exponentially weighted average and GARCH. Along with this they showed how long covariance matrices are important for global risk management systems. The results indicated that the EWMA are better in predicting long term return distributions. The estimates produced by GARCH model are more conservative reflecting $1 \%$ value at risk measure.

Baillie et al. (1996) projected the fractionally integrated generalized autoregressive conditional heteroscedasticity (FIGARCH) model by generalizing the IGARCH model to allow for persistence in the conditional variance. The results indicated that it is advisable to investigate whether long memory property of volatility in financial time series can affect the measurement of market risk or not.

Based on the above literature, the objectives of the research were set.

\subsection{Objectives}

1. To estimate volatility based on different GARCH based models for emerging nation's viz. China, India, Turkey, Mexico, Indonesia, Russia, and Brazil.

2. To find out best fit GARCH model for estimation of volatility.

3. To find out the Value at Risk for emerging nation's viz. China, India, Turkey, Mexico, Indonesia, Russia, and Brazil.

\subsection{Research Methodology}

For the study purpose a sample of six emerging stock markets was taken and the data for the same (index returns) was taken from the year 2000 to 2012. Individual stock exchange (representative) of each nation during the study period acted as a sample element for evaluating GARCH based model in VaR estimation. Purposive sampling technique was used for study purpose. Secondary data sources were used to collect the data regarding closing stock prices of each index.

After collecting the data, following tools were applied for analysis purpose;

1) Checking for normality through Jarque Bera.

2) Stationary of data will be checked by using ADF and PP.

Following GARCH models were evaluated;

- $\quad \operatorname{GARCH}(\mathrm{p}, \mathrm{q})$ model

$\mathrm{h}_{\mathrm{t}}=\omega+\alpha(\mathrm{L}) \varepsilon_{\mathrm{t}}^{2}+\beta(\mathrm{L}) \mathrm{h}_{\mathrm{t}}$

- $\quad \operatorname{EGARCH}(\mathrm{p}, \mathrm{q})$ model

$\mathrm{h}_{\mathrm{t}}=\omega+[1-\beta(\mathrm{L})]^{-1}[1+\alpha(\mathrm{L})] \mathrm{g}\left(\eta_{\mathrm{t}-1}\right)$

- $\quad \operatorname{IGARCH}(\mathrm{p}, \mathrm{q})$ Model 
$\varphi(\mathrm{L})(1-\mathrm{L}) \varepsilon_{\mathrm{t}}^{2}=\omega+[1-\beta(\mathrm{L})] \mathrm{v}_{\mathrm{t}}$

- $\quad$ FIEGARCH (p, d, q) model

$\mathrm{h}_{\mathrm{t}}=\omega+\varphi(\mathrm{L})^{-1}(1-\mathrm{L})^{-\mathrm{d}}[1+\zeta(\mathrm{L})] \mathrm{g}\left(\eta_{\mathrm{t}-\mathrm{i}}\right)$

VaR was estimated using the below given formula;

$\mathrm{VaR}=\mathrm{N}_{\mathrm{a}} \sigma 3 \mathrm{~V}$

The following are an indication of the steps involved in implementing the EngleGranger (E.G) test, details descriptions of each steps will follow in the subsequent sections:

1. First step is to follow the presence of a unit root in each variable in data under investigation, using Augmented Dickey-Fuller (ADF) and test the variables by Phillips- Perron (PP).

2. Differencing the data in the presence of unit root and conduct the (ADF) test again on the differenced data.

3. Exclude the variables where one of the variables is non stationary and other is stationary.

4. Calculated the log returns to apply the GARCH further as it is mandatory.

\subsection{Testing for Unit Root}

The data series of index returns for China, India, Turkey, Mexico, Indonesia, Russia, and Brazil were checked for stationary by using ADF test. The results of the same are summarized below in Table 1 .

<TABLE 1 HERE>

The ADF and PP unit root test are applied to data. Both unit root test indicates that null hypothesis is rejected at level, thus further tests at level were applied. From results we can conclude that data is stationary of order I (0). T-statistic value is more than critical value shows that data is stationer.

\subsection{Descriptive Statistics}

Descriptive statistics results for all 6emerging market under study namely, Brazil, China, India, Mexico, Turkey and Russia are summarized in the Table 2.

\section{$<$ TABLE 2 HERE $>$}

The descriptive statistics results for all six emerging market under study namely, Brazil, China, India, Mexico, Turkey and Russia shows that the S.D for Brazil and Mexico is significantly low. As mean of Brazil and Mexico is -0.115780 and S.D is 0.988058. Mean of China, India, Turkey and Russia is-0.351083,-0.320585,-0.452892 and -0.066997 respectively and S.D. is $1.068014,1.035493,1.055038$ and 1.031289 respectively. This shows that there is moderate variability in these markets.

The value of skewness for all the emerging markets is negative which shows that the data is not normally distributed. This implies that the negative variables had extreme values during the study.

From the Table 2 it is determined that the distribution for all the markets is LEPTOKURTIC as all the values are more than 3 for all the emerging markets. If the values would have been less than 3 then the distribution would be PLATYKURTIC. 
The Jarque Bera test is applied to measure the difference of skewness and kurtosis of the data series with those from the normal distribution.

\section{Autocorrelation Functions (ACFs) and Partial-autocorrelation Functions (PACFs)}

The autocorrelation function (ACF) is a set of correlation coefficients between the series and lags of itself over time. The partial autocorrelation function (PACF) is the partial correlation coefficients between the series and lags of itself over time. The index return data for all the nations is tested for autocorrelation (see Tables 3 to 8). We test the presence of autocorrelation in log returns using the ACF, PACF.

- Q statistic tests the null hypothesis of no auto correlation for China. The Table 3 shows there is no auto correlation at lag 1.

- Q statistic tests the null hypothesis of no auto correlation for Brazil. The Table 4 shows there is no auto correlation at lag 1.

- Q statistic tests the null hypothesis of no auto correlation for India. The Table 5 shows there is auto correlation at all the lag.

- Q statistic tests the null hypothesis of no auto correlation for Mexico. The Table 6 shows there is no auto correlation at lag 1 .

- Q statistic tests the null hypothesis of no auto correlation Russia. The Table 7 shows there is auto correlation at all the lag.

- Q statistic tests the null hypothesis of no auto correlation Turkey. The Table 8 shows there is auto correlation at all the lag.

\subsection{ARCH LM Test}

This is a Lagrange multiplier (LM) test for autoregressive conditional heteroskedasticity (ARCH) in the residuals (Engle 1982). This particular specification of heteroskedasticity was motivated by the observation that in many financial time series, the magnitude of residuals appeared to be related to the magnitude of recent residuals. ARCH in itself does not invalidate standard LS inference. However, ignoring ARCH effects may result in loss of efficiency.

The Obs*R-squared statistic is Engle's LM test statistic, computed as the number of observations times the from the test regression. The arch $1 \mathrm{~m}$ test, test's the null hypothesis of no arch effect present. The table 9 shows that there is presence of Arch effect or not:

The Table 9 shows that there is Arch effect present in all the emerging equity markets viz. India, Brazil, Mexico, Russia and Turkey except for China. Since there are ARCH effects in the stock return data, we can proceed with estimation of GARCH models. We estimate the following symmetric GARCH models: the GARCH $(1,1)$ model with normal and Student's $t$-distribution and the GARCH-M model as well as the following asymmetric GARCH models: the EGARCH $(1,1)$ model with normal and Student's $t$ distribution distribution, the GARCH-GJR model and the APARCH model.

\subsection{Models of Changing Variance}

Thupayagale in his paper talked about the seminal contributions of Engel (1982) and Bollerslev (1986) in modelling of financial asset returns has been cast in the generalized autoregressive conditional heteroskedasticity. For asset returns, the GARCH class of models involves the estimation of an equation for asset returns and a conditional variance $\square$ ht $\square$ specification. The dynamics of ht for a wide range of financial asset returns has been found to be adequately modelled as a $\operatorname{GARCH}(1,1)$ process. 


\subsection{GARCH $(p, q)$ Model}

The standard GARCH (p, q) model forecasts of volatility. The GARCH $(1,1)$ model is estimated for the given time series and results of the same are discussed in the Table 9. The stationarity of $\operatorname{GARCH}(1,1)$ is checked by $\alpha 1+\beta 1<1$. From the table 10 it can be seen that GARCH model is stationary for all the cases. EViews reports the DurbinWatson (DW) statistic as a part of the standard regression output. The Durbin-Watson statistic is a test for first-order serial correlation. More formally, the DW statistic measures the linear association between adjacent residuals from a regression model. The Durbin-Watson is a test of the hypothesis in the specification.

The Table 10 shows that there is no serial correlation in Brazil and Mexico as value of Durbin Watson statistic is around 2. Except these in all other Emerging equity markets viz. India, China, Russia and Turkey there exist positive serial correlation as the Durbin Watson static is below 2 .

\subsection{E-GARCH Test}

Formally, an $\operatorname{EGARCH}(\mathrm{p}, \mathrm{q})$ :

$\log \sigma_{t}^{2}=\omega+\sum_{k=1}^{q} \beta_{k} g\left(Z_{t-k}\right)+\sum_{k=1}^{p} \alpha_{k} \log \sigma_{t-k}^{2}$

where $g\left(Z_{t}\right)=\theta Z_{t}+\lambda\left(\left|Z_{t}\right|-E\left(\left|Z_{t}\right|\right)\right), \sigma_{t}^{2}$ is the conditional variance, $\omega$,

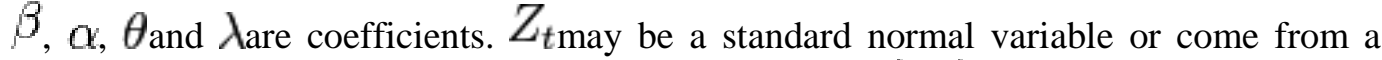
generalized error distribution. The formulation for $g\left(Z_{t}\right)$ allows the sign and the

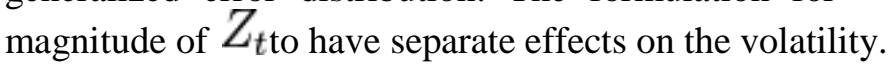

The EGARCH model has a number of advantages over the $\operatorname{GARCH}(p, q)$ model. The most important one is its logarithmic specification, which allows for relaxation of the positive constraints among the parameters. Another advantage of the EGARCH model is that it incorporates the asymmetries in stock return volatilities. Another advantage of the EGARCH model is that it successfully captures the persistence of volatility shocks. Based on these advantages, we apply the EGARCH model for estimating the volatility of the Emerging equity market.

Table 11 and 12: Here the null hypothesis states that coefficients are not significant. From the above two tables it can be seen that all Coefficient are significant for India, China, Mexico and Turkey. For Brazil it is not significant up to lag 5 as the probability values are more than $5 \%$. For Russia it is significant at all levels except at lag 3 .

The above tables also show that there is no serial correlation in Brazil, china, Mexico and Russia as value of Durbin Watson statistic is around 2. While for rest of the Emerging equity markets viz. India and Turkey there exist positive serial correlation as the Durbin Watson static is below 2 . 


\subsection{P-GARCH}

In the Power ARCH model, the power parameter $\delta$ of the standard deviation can be estimated rather than imposed.

Table 13 and 14: The above table shows that there is positive serial correlation in all the Emerging equity markets viz. India, China, Russia and Turkey as the Durbin Watson static is below 2 for all.

As per the observation of above table the coefficient is significant for India at all Lags. For Brazil it is not significant at any lag except at lag 5. For China coefficient is significant only at lag 1 and 2. Mexico's coefficient value is not significant till lag 4; it becomes significant at lag 5. For Russia it is significant at all lags except at lag1. And for turkey coefficient is significant at lag 1,2 and 5 .

\subsection{Comparison of Best Fit Model}

The comparison of the GARCH models are made in terms of their Akaike Information Criterion (AIC) and Schwarz Information Criterion (SIC) values in the estimation stage and forecast performances in the forecasting stage.

It can be concluded from table 15 that both the AIC and SIC values from EGARCH model are smaller than that from GARCH $(1,1)$ and PARCH models. Therefore, it shows that EGARCH is a better model than GARCH $(1,1)$ and PARCH for estimating daily stock indices of emerging equity markets.

\subsection{Value at Risk}

An important and topical strand of recent empirical research has focused on the calculation of value-at-risk (VaR) in these markets. VaR models were developed to estimate the exposure of a portfolio to market risk (Jorion, 2007). VaR has also emerged as standard quantitative measure of market risk within most financial institutions; moreover, this method also forms the basis for a host of risk controls (e.g., position limits and margin requirements) (IMF, 2007). There are various methods, or approaches, to measure VaR. Differences among these approaches arise from the model applied to the estimation of the expected changes in prices. Table 16 in annexure presents the VaR failure rates for the emerging equity markets, reported at the 95 percent probability levels.

On the basis of above table we can compare the VaR of the emerging equity markets of India, Brazil, China, Mexico, Russia and Turkey. The lower VaR value signifies lower failure rate in stock market. Thus on the basis of observation of above table Russia has a VaR value -2043939.735 which signifies that it has lowest failure rate of all other emerging equity markets.

\subsection{Conclusion}

This research has been developed to estimate the VaR of the stock returns in the selected nations (emerging equity markets). Ten years data of six emerging equity markets namely Brazil, china, India, Mexico, turkey and Russia has been taken for study purpose. VaR is calculated to estimate the probability of risk in the portfolio of these nations. Initially for data checking purpose, ADF and PP tests were applied to check the stationary of data, the result of which indicated that the data was stationary at level. Further descriptive statistics were applied to check the normality of data. This included Skweness, kurtosis 
and Jarque Bera. The ARCH (LM) test i.e. Lagrange multiplier (LM) test for autoregressive conditional heteroskedasticity in residuals was applied. The data was normally distributed. The arch effect was found in all the emerging equity markets which implied that there was impact of previous day's returns on the present returns.

The ARCH effect was found and thus the basic condition for the GARCH testing was satisfied and furthers the GARCH models were applied for volatility testing. The GARCH model considered for the testing were GARCH $(1,1)$, EGARCH and PGARCH. For the given data series, EGARCH model was found to be best fit as the value of AIC and SC is lowest for this model. VaR has been calculated to estimate the market risk associated with these models. This was done by using historical method of calculating VaR. It was found that the Russia has least market risk or least failure rate as the value of VaR was lowest. The reason for this could be lesser impact of global financial crises in Russia. The another reason could be Investors in the Russian stock market misprice consumer sector shares and this is a big buying opportunity, according to Russian strategists and Wealthy households are also more prevalent in Russia; 15\% of them have income above $\$ 50,000$ compared with $5 \%$ in Brazil, $2 \%$ in China and $1 \%$ in India. Similar researches has been conducted by Azizan et al. (2012), Kourouma et al. (2011), Dimitrakopoulos et al. (2010), Thupayagale (2010), etc. on the similar topics. Similar results were obtained by Gnamassou et al in 2010 which showed that Historical Simulation, GARCH models techniques showed poor performance except when used with Student distribution.

The serial correlation is often (though incorrectly) associated with market inefficiencies, implying a violation of the Random Walk Hypothesis and the presence of predictability in returns. The serial correlation is associated with illiquidity too.

Positive serial correlation means that positive returns tend to follow positive returns (a momentum type of property). Negative serial correlation means that positive returns tend to be followed by negative returns (a reversal or "correction" property). Both Conrad and Kaul (1988) and Lo and MacKinlay (1988) examine weekly returns of NYSE stocks and find positive serial correlation over short horizons.

Although short- to intermediate-horizon returns suggest momentum in stock market prices, studies of long-horizon returns (i.e., returns over multiyear periods) by Fama and French (1988) and Poterba and Summers (1988) indicate pronounced negative long-term serial correlation in the performance of the aggregate market. The latter result has given rise to a "fads hypothesis," which asserts that the stock market might overreact to relevant news. Such overreaction leads to positive serial correlation (momentum) over short time horizons. Subsequent correction of the overreaction leads to poor performance following good performance and vice versa. The corrections mean that a run of positive returns eventually will tend to be followed by negative returns, leading to negative serial correlation over longer horizons. These episodes of apparent overshooting followed by correction give the stock market the appearance of fluctuating around its fair value (as per a chapter in highered mcgrawhill.com)

The non-existence of serial correlation in returns for Brazil and Mexico show that the day returns is independent of history. Predicting the future trends of returns in such markets is a difficult task. But for India, Turkey and China, with (positive) serial correlation, the probability of a "+"following a "+" is greater than following a "-". 
As per an article published at pages.stern.nyu.edu, stating the viewpoint of investment strategy, serial correlations can sometimes be exploited to earn excess returns. A positive serial correlation would be exploited by a strategy of buying after periods with positive returns and selling after periods with negative returns. A negative serial correlation would suggest a strategy of buying after periods with negative returns and selling after periods with positive returns. Since these strategies generate transactions costs, the correlations have to be large enough to allow investors to generate profits to cover these costs. It is therefore entirely possible that there be serial correlation in returns, without any opportunity to earn excess returns for most investors.

\section{References}

- (http://highered.mcgrawhill.com/sites/dl/free/007338240x/773409/Sample Chapter_8_New.pdf)

- Aggrawal, R., Inclan, C., \& Leal, R. (1999). Volatility in emerging Stock Markets. Journal of Financial and Quantitative Analysis, 34, 33-55.

- Alexander, C. O., \& Leigh, C. T. (1997). On the covariance matrices used in value at risk models. The Journal of Derivatives, 4(3), 50-62.

- Altar, M., \& Iorgulescu, F. (2008). Value at risk: A comparative Analysis. Academy of Economic Studies, Bucharestdofin Master Program. Asociatia Generalaa Economistilor din Romania - AGER, Vol. 12(565), 15-32, December.

- Andjelić, G., Djaković, V., \& Radišić, S. (2010). Application of VaR in emerging markets: A case of selected central and Eastern European countries. African Journal of Business Management, 4(17), 3666-3680.

- Assaf., A. (2006). Extreme observations in the MENA stock markets and their implication for VaR measures. MEEA held with the Allied Social Science Association Annual Meeting, University of Windsor, Ontario, Canada.

- Azizan, N. A., Kuang, L. C., \& Ahmed, Z. (2012). Forecasting portfolio risk estimation by using Garch and Var methods. Research Journal of Finance and Accounting, 3(11), 62-69.

- Baillie, R. T., Bollerslev, T., \& Mikkelsen, H. O. (1996). Fractionally integrated generalized autoregressive conditional heteroscedasticity. Journal of Econometrics, 74, 3-30.

- Bekaert, G., \& Harvey, C. R. (1997). Emerging equity market volatility. Journal of Financial Economics, 43(1), 29-77.

- Benavides, G., \& Banco de México. (2007). GARCH processes and value at risk: An empirical analysis for Mexican interest rates futures. Panorama Socioeconómico, 25(35), 92-105.

- Berkowitz, J., \& O'Brien, J. (2001). How accurate are value-at-risk models at commercial banks?. Economics Department, 12, 75-90.

- Burns, P. J. (2002). The quality of value at risk via univariate GARCH. Managerial Finance, 34(7), 489-497.

- Carchano, O. S., Rachev, Y., Kim, E. Sun., \& F. Fabozzi. (2010). Forecasting $\mathrm{VaR}$ in spot and futures equity markets. Journal of Portfolio Management.

- Chan, N. H., Deng, S. J., Peng, L., \& Xia, Z. (2001). Interval estimation of value-at-risk based on GARCH models with heavy tailed innovations. 
School of Industrial and Systems Engineering, Georgia Institute of Technology. Georgian Mathematical Journal 13.

- Chen. C. T., Hae. C. C., \& Hsieh, C. S. (2003). Forecasting value at risk (VAR) in the futures market using hybrid method of neural networks and GARCH model. Department of Management Information System at Far East. Tainan County, Taiwan,Paper, ID 3050.

- Choudhry, M. (2001). The bond and money markets: Strategy, trading, analysis. Economics Department, 19, 45-55.

- DANIELSSON. Jon and Casper G. DE VRIES. (2000).Value-at-risk and extreme returns. Workshop Participants at the London School of Economics, University of Edinburgh, Cambridge University, Economics and Business, Universitat Pompeu Fabra, Papers 62, Edinburgh School of Economics, University of Edinburgh.

- Dimitris, N. D., Manolis G. K., \& Spyros I. S. (2010). Value at risk models for volatile emerging markets equity portfolios. The Quarterly Review of Economics and Finance, 50, 515-526.

- Eksi, Z., Irem, Y., \& Kasirga, Y. (2005). Alternative risk measures and extreme value theory in finance: Implementation on ISE 100 Index. Selected Proceedings of the First International Conference on Business, Management and Economics. Yasar University. Izmir.

- Ergen, Ibrahim. (2010). VaR prediction for emerging stock markets: GARCH filtered skewed t-Distribution and GARCH filtered EVT method supervision regulation and credit. Financial Economist Supervision, Regulation and Credit/Risk and Policy Analysis Unit Federal Reserve Bank of Richmond/Baltimore Branch.

- F. J. Fabozzi, Radu Tunaru, \& Tony Wu. (2004). Modeling Volatility for the Chinese equity markets. Annals of Economics and Finance, 5(1), 79-92.

- Fama, E. F., \& French, K. R. (1988). Dividend yields and expected stock returns. Journal of Financial Economics, 22(1), 3-25.

- Fernandez, V. (2003). Extreme value theory and value at risk. Revista de Analisis Economico - Economic Analysis Review, Ilades-Georgetown University, Economics Department, 18(1), 57-85.

- Floros, C. (2008). Modelling volatility using GARCH models: Evidence from Egypt and Israel. Middle Eastern Finance and Economics, Issue 2, Euro Journals Publishing, Inc.

- Gencay, R., \& Selcuk, F. (2004). Extreme value theory and value-at-risk: Relative performance in emerging markets. Department of Economics, University of Windsor, 401 Sunset Avenue, Windsor, Ontario, Canada. International Journal of Forecasting, 20, 287-303.

- Giot, P., \& Laurent, S. (2003). Modelling daily value-at-risk using realized volatility and arch type models. Universiteit Maastricht Meteor Working Paper No. RM/01/026.

- Gnamassou, Y. T. (2010). Value at risk prediction: A comparison of alternative techniques applied to a large sample of individual stock data. Paper, HEC Montreal.

- Goorbergh. Rob., \& Peter, V. (1999). Value-at-risk analysis of stock returns historical simulation, variance techniques or tail index estimation? Netherlands Central Bank, Research Department.

- http://pages.stern.nyu.edu/ adamodar/New Home Page/invfables/pricepatt erns.htm 
- Hull, J. C. (2006). Options, futures, and other derivatives. Pearson Prentice Hall. 6th ed.

- Janak Raj, Sarat Dhal, (2008), Integration of India's stock market with global and majorregional markets. BIS paper No. 42, Bank of International Settlement.

- Kang, S. H., \& Yoon, S. -M. (2009). Value-at-risk analysis for Asian emerging markets: Asymmetry and fat tails in returns innovation ,The Korean Economic Review 25(2).

- Kasman. A. (2009). Estimating value-at-risk for the Turkish stock index futures in the presence of long memory volatility. Department of Economics Faculty of Business, DokuzEylül University, Turkey, Adnan Kasman / Central Bank 2 Review, 1-14.

- Kourouma, L., Dupre D., Sanfilippo, G., \& Taramasco, T. (2011). Extreme value at risk and expected shortfall during financial crisis. UnitéMixte de Recherche CNRS, halshs-00658495, version $1-10$.

- Kuester. Keith, Stefan Mittnik \& Marc S. Paolella. (2005). Value-at-pisk Prediction: A comparison of alternative strategies. Faculty of Economics and Business Administration, Department of Statistics, Institute of Statistics and Econometrics, University of Kiel, Germany.

- McAleer \& L. Oxley (2010). Contributions to financial econometrics: Theoretical and practical issues. Blackwell, Oxford, 9-33.

- McMillan D., \& Pako T. (2010). Evaluating stock index return value-at-risk estimates in south Africa: Comparative evidence for symmetric, asymmetric and long memory garch models. Institute for Financial Management and Research, Journal of Emerging Market Finance, 9(325).

- Mecagni, M., \& Sourial, M.S., (1999). The Egyptian stock market: Efficiency tests and volatility effects. IMF Working Paper, WP/99/48.

- Mike K.P \& Philip L.H. (2006). Empirical analysis of GARCH models in value at risk estimation. Journal of International Financial Markets, Institutions and Money, 16, (2), 180-197.

- Morimoto Takayuki \& Yoshinori Kawasaki. (2009). Empirical comparison of multivariate GARCH models for estimation of intraday value at risk.

- Orhan, M. and Köksal, B., (2012). "A Comparison of GARCH Models for VaR Estimation”,Expert Systems with Applications, 39, 3582-2592.

- Poterba, J. M., \& Summers, L. (1987). Mean reversion in stock return: Evidence and implications. Unpublished manuscript (National Bureau of Economic Research, Cambridge, MA)

- Rampersad, T., \& Patrick, K. W. (2005). The efficacy of value at risk models in Caribbean Equity Markets/ First Citizens' Bank, Group Market Risk Department, Sir Arthur Lewis Institute of Social \& Economic Studies, University of the West Indies, St. Augustine, Port-of-Spain, Trinidad \& Tobago.

- Rombouts Jeroen V.K. Marno Verbeek. (2004). Evaluating portfolio valueat-risk using semi-parametric GARCH Models. Cahier de recherche no IEA04-14.

- Roy. Indrajit. (2009). Estimation of value at risk for the Indian capital market: Filtered historical simulation approach using GARCH model with suitable mean specification. Department of Statistics and Information Management, Reserve Bank of India, RBI Occasional papers 32(2). 
- Seyyed Ali Paytakhti Oskooe \& Ali Shamsavari. (2011). Asymmetric effects in emerging stock markets: The case of Iran stock market. School of Economics, Kingston University London, International Journal of Economics and Finance 3 (6).

- Singh, A. K., David, E. A., \& Robert, J. P. (2011). Value at risk estimation using extreme value theory. 19th International Congress on Modelling and Simulation, 7106, Perth, Australia.

- $\quad$ St. Pierre, Eilleen F. (1998). "Estimating EGARCH-M Models: Science or Art". The Quarterly Review of Economics and Finance 38 (2): 167-180. doi:10.1016/S1062-9769(99)80110-0

- Tae-Hwy Lee, Yong Bao, Burak Saltoglu (2006). Evaluating predictive performance of value-at-risk models in emerging markets: a reality check Journal of Forecasting - J FORECASTING , 25(2), 101-128.

- Tagliafichi, R. A. (2002). Betas calculated with Garch models provides new parameters for a Portfolio selection with an Efficient Frontier. Av. Cordoba 1646 - 6to 2091055 - Buenos Aires Argentina.

- Thupayagale P. (2010). Evaluation of GARCH-based models in value-atrisk estimation: Evidence from emerging equity markets. Investment Analysts Journal - No. 72.

- Ünal, Gözde. (2011).Value-at-risk forecasts: A comparison analysis of extreme-value versus classical approaches. The Journal of Risk Model Validation. 5(3),59-76.

- Xiao, Z. and Koenker, R. (2009). Conditional Quantile Estimation for Generalized Autoregressive Conditional Heteroscedasticity Models, Journal of the American Statistical Association, Vol. 104, No. 488, 1696-1712.

- $\quad$ Žiković, S., \& Bora, A. (2009). Global financial crisis and VaR performance in emerging markets: A case of EU candidate states. Turkey and Croatia Zb. rad. Ekon. fak. Rij, 27(1), 149-170. 


\section{(Tables \& Figures)}

Table 1: Unit root testing

\begin{tabular}{|c|c|c|c|c|c|c|c|}
\hline \multirow[t]{2}{*}{ Variables } & \multicolumn{3}{|c|}{ ADF Test } & \multicolumn{3}{|c|}{ PP Test } & \multirow{3}{*}{$\begin{array}{c}\text { Order } \\
\text { of } \\
\text { Integr-ation }\end{array}$} \\
\hline & \multicolumn{3}{|c|}{ H0: Variable is nonstationary } & \multicolumn{3}{|c|}{ Ho: Variable is nonstationary } & \\
\hline Exogenous & Constant & Constant, Linear Trend & None & Constant & Constant, Linear Trend & None & \\
\hline INDIA & -14.30651 & -14.33401 & -8.828596 & -63.35959 & -63.31803 & -70.41372 & \multirow[t]{2}{*}{$I(0)$} \\
\hline BRAZIL & -17.75470 & -18.31283 & -17.11781 & -63.26332 & -61.89770 & -65.06997 & \\
\hline MEXICO & -17.71642 & -18.31773 & -17.05070 & -63.38477 & -61.97070 & -65.23971 & \multirow[t]{2}{*}{$\mathbf{I}(\mathbf{0})$} \\
\hline CHINA & -11.58462 & -11.67822 & -7.775729 & -69.96653 & -69.29921 & -78.60912 & \\
\hline TURKEY & -8.739749 & -11.05677 & -5.888221 & -69.29599 & -68.36446 & -76.11992 & \multirow[t]{2}{*}{$\mathbf{I}(\mathbf{0})$} \\
\hline RUSSIA & -17.91972 & -17.94657 & -12.41631 & -63.31589 & -63.25268 & -63.60358 & \\
\hline \multicolumn{8}{|c|}{ Asymptotic critical values } \\
\hline & -2.88 & -3.44 & -1.94 & -2.88 & -3.44 & -1.94 & \\
\hline & -2.58 & -3.14 & -1.61 & -2.57 & -3.14 & -1.61 & \\
\hline & & & & . & & & \\
\hline
\end{tabular}


Table 2: Descriptive statistics

\begin{tabular}{|l|c|c|c|c|c|c|}
\hline & BRAZIL & CHINA & INDIA & MEXICO & TURKEY & RUSSIA \\
\hline Mean & -0.115780 & -0.351083 & -0.320585 & -0.115780 & -0.452892 & -0.066997 \\
\hline Std.Dev. & 0.988058 & 1.068014 & 1.035493 & 0.988058 & 1.055038 & 1.031289 \\
\hline Skewness & -1.101618 & -1.206101 & -1.107833 & -1.101618 & -1.161277 & -1.063925 \\
\hline Kurtosis & 4.882480 & 5.550387 & 5.231928 & 4.882480 & 6.077385 & 5.348105 \\
\hline $\begin{array}{l}\text { Jarque- } \\
\text { Bera }\end{array}$ & 1102.934 & 1618.446 & 1298.975 & 1102.934 & 1952.212 & 1284.455 \\
\hline Prob. & 0.000000 & 0.000000 & 0.000000 & 0.000000 & 0.000000 & 0.000000 \\
\hline
\end{tabular}

Table3: Correlogram of Daily Stock Returns of China

\begin{tabular}{|r|c|c|c|c|}
\hline Lag & AC & PAC & Q-Stat & Prob \\
\hline 1 & 0.027 & 0.027 & 2.4035 & 0.121 \\
\hline 2 & 0.134 & 0.134 & 61.294 & 0.000 \\
\hline 3 & 0.115 & 0.110 & 104.27 & 0.000 \\
\hline 4 & 0.114 & 0.095 & 146.68 & 0.000 \\
\hline 5 & 0.089 & 0.060 & 172.37 & 0.000 \\
\hline 6 & 0.106 & 0.071 & 209.17 & 0.000 \\
\hline 7 & 0.100 & 0.064 & 241.72 & 0.000 \\
\hline 8 & 0.128 & 0.089 & 295.72 & 0.000 \\
\hline 9 & 0.081 & 0.037 & 317.09 & 0.000 \\
\hline 10 & 0.116 & 0.064 & 361.48 & 0.000 \\
\hline 11 & 0.098 & 0.048 & 392.79 & 0.000 \\
\hline
\end{tabular}


IRA-International Journal of Management \& Social Sciences

\begin{tabular}{|r|r|r|r|r|}
\hline 12 & 0.107 & 0.051 & 430.08 & 0.000 \\
\hline 13 & 0.074 & 0.017 & 448.21 & 0.000 \\
\hline 14 & 0.075 & 0.011 & 466.69 & 0.000 \\
\hline 15 & 0.076 & 0.016 & 485.54 & 0.000 \\
\hline 16 & 0.107 & 0.050 & 522.87 & 0.000 \\
\hline 17 & 0.082 & 0.030 & 545.17 & 0.000 \\
\hline 18 & 0.101 & 0.041 & 578.88 & 0.000 \\
\hline 19 & 0.065 & 0.005 & 592.82 & 0.000 \\
\hline 20 & 0.095 & 0.030 & 622.38 & 0.000 \\
\hline 21 & 0.066 & 0.009 & 636.75 & 0.000 \\
\hline 22 & 0.065 & 0.001 & 650.50 & 0.000 \\
\hline 23 & 0.077 & 0.017 & 669.75 & 0.000 \\
\hline 24 & 0.046 & -0.015 & 676.85 & 0.000 \\
\hline 25 & 0.087 & 0.031 & 701.75 & 0.000 \\
\hline 26 & 0.094 & 0.042 & 730.83 & 0.000 \\
\hline 27 & 0.062 & 0.008 & 743.54 & 0.000 \\
\hline 28 & 0.055 & -0.010 & 753.33 & 0.000 \\
\hline 29 & 0.043 & -0.018 & 759.47 & 0.000 \\
\hline 30 & 0.126 & 0.076 & 811.79 & 0.000 \\
\hline 31 & 0.078 & 0.037 & 831.60 & 0.000 \\
\hline 32 & 0.085 & 0.030 & 855.52 & 0.000 \\
\hline 33 & 0.054 & -0.009 & 865.16 & 0.000 \\
\hline 34 & 0.052 & -0.015 & 874.15 & 0.000 \\
\hline 35 & 0.081 & 0.026 & 895.74 & 0.000 \\
\hline 36 & 0.047 & -0.009 & 902.91 & 0.000 \\
\hline
\end{tabular}


IRA-International Journal of Management \& Social Sciences

Table 4: Correlogram of Daily Stock Returns of Brazil

\begin{tabular}{|c|c|c|c|c|}
\hline Lag & $\mathrm{AC}$ & PAC & Q-Stat & Prob \\
\hline 1 & -0.006 & -0.006 & 0.1251 & 0.724 \\
\hline 2 & 0.084 & 0.084 & 22.172 & 0.000 \\
\hline 3 & 0.058 & 0.059 & 32.627 & 0.000 \\
\hline 4 & 0.092 & 0.087 & 59.289 & 0.000 \\
\hline 5 & 0.064 & 0.057 & 72.105 & 0.000 \\
\hline 6 & 0.095 & 0.082 & 100.89 & 0.000 \\
\hline 7 & 0.039 & 0.024 & 105.78 & 0.000 \\
\hline 8 & 0.053 & 0.029 & 114.79 & 0.000 \\
\hline 9 & 0.059 & 0.038 & 125.73 & 0.000 \\
\hline 10 & 0.089 & 0.066 & 150.52 & 0.000 \\
\hline 11 & 0.048 & 0.028 & 157.80 & 0.000 \\
\hline 12 & 0.059 & 0.031 & 169.01 & 0.000 \\
\hline 13 & 0.035 & 0.009 & 172.79 & 0.000 \\
\hline 14 & 0.064 & 0.033 & 185.75 & 0.000 \\
\hline 15 & 0.070 & 0.045 & 201.31 & 0.000 \\
\hline 16 & 0.032 & 0.002 & 204.56 & 0.000 \\
\hline 17 & 0.077 & 0.049 & 223.54 & 0.000 \\
\hline 18 & 0.049 & 0.023 & 231.17 & 0.000 \\
\hline 19 & 0.040 & 0.008 & 236.27 & 0.000 \\
\hline 20 & 0.059 & 0.027 & 247.50 & 0.000 \\
\hline 21 & 0.038 & 0.006 & 252.17 & 0.000 \\
\hline 22 & 0.018 & -0.014 & 253.23 & 0.000 \\
\hline 23 & 0.082 & 0.051 & 274.69 & 0.000 \\
\hline 24 & 0.018 & -0.009 & 275.69 & 0.000 \\
\hline 25 & 0.042 & 0.008 & 281.29 & 0.000 \\
\hline 26 & 0.035 & 0.008 & 285.29 & 0.000 \\
\hline 27 & 0.049 & 0.017 & 292.86 & 0.000 \\
\hline 28 & 0.062 & 0.039 & 305.04 & 0.000 \\
\hline 29 & 0.052 & 0.021 & 313.56 & 0.000 \\
\hline 30 & 0.031 & 0.003 & 316.53 & 0.000 \\
\hline 31 & 0.025 & -0.006 & 318.54 & 0.000 \\
\hline 32 & 0.050 & 0.018 & 326.64 & 0.000 \\
\hline 33 & 0.031 & 0.001 & 329.77 & 0.000 \\
\hline 34 & 0.034 & 0.003 & 333.42 & 0.000 \\
\hline 35 & 0.033 & 0.003 & 336.81 & 0.000 \\
\hline 36 & 0.016 & -0.009 & 337.62 & 0.000 \\
\hline
\end{tabular}


IRA-International Journal of Management \& Social Sciences

Table 5: Correlogram of Daily Stock Returns of India

\begin{tabular}{|l|l|l|l|l|}
\hline Lag & AC & PAC & Q-Stat & Prob \\
\hline 1 & 0.119 & 0.119 & 44.647 & 0.000 \\
\hline 2 & 0.113 & 0.101 & 85.532 & 0.000 \\
\hline 3 & 0.116 & 0.094 & 127.89 & 0.000 \\
\hline 4 & 0.110 & 0.080 & 166.36 & 0.000 \\
\hline 5 & 0.123 & 0.087 & 214.30 & 0.000 \\
\hline 6 & 0.125 & 0.083 & 263.87 & 0.000 \\
\hline 7 & 0.148 & 0.101 & 333.81 & 0.000 \\
\hline 8 & 0.090 & 0.030 & 359.37 & 0.000 \\
\hline 9 & 0.074 & 0.014 & 376.75 & 0.000 \\
\hline 10 & 0.111 & 0.056 & 416.10 & 0.000 \\
\hline 11 & 0.112 & 0.053 & 455.81 & 0.000 \\
\hline 12 & 0.084 & 0.020 & 478.44 & 0.000 \\
\hline 13 & 0.072 & 0.007 & 494.77 & 0.000 \\
\hline 14 & 0.105 & 0.046 & 529.87 & 0.000 \\
\hline 15 & 0.083 & 0.023 & 551.58 & 0.000 \\
\hline 16 & 0.077 & 0.017 & 570.42 & 0.000 \\
\hline 17 & 0.136 & 0.077 & 629.32 & 0.000 \\
\hline 18 & 0.082 & 0.015 & 650.62 & 0.000 \\
\hline 19 & 0.091 & 0.030 & 677.20 & 0.000 \\
\hline 20 & 0.082 & 0.019 & 698.83 & 0.000 \\
\hline 21 & 0.104 & 0.037 & 733.08 & 0.000 \\
\hline 22 & 0.077 & 0.008 & 752.14 & 0.000 \\
\hline 23 & 0.059 & -0.008 & 763.20 & 0.000 \\
\hline 24 & 0.080 & 0.011 & 783.61 & 0.000 \\
\hline 25 & 0.055 & -0.009 & 793.42 & 0.000 \\
\hline 26 & 0.074 & 0.016 & 810.89 & 0.000 \\
\hline 27 & 0.062 & 0.000 & 823.27 & 0.000 \\
\hline 28 & 0.046 & -0.017 & 830.01 & 0.000 \\
\hline 29 & 0.042 & -0.012 & 835.76 & 0.000 \\
\hline 30 & 0.053 & 0.007 & 844.83 & 0.000 \\
\hline 31 & 0.090 & 0.040 & 871.02 & 0.000 \\
\hline 32 & 0.079 & 0.029 & 891.25 & 0.000 \\
\hline 33 & 0.047 & -0.006 & 898.28 & 0.000 \\
\hline 34 & 0.074 & 0.023 & 915.74 & 0.000 \\
\hline 35 & 0.089 & 0.042 & 941.12 & 0.000 \\
\hline 36 & 0.056 & -0.001 & 951.01 & 0.000 \\
\hline
\end{tabular}


IRA-International Journal of Management \& Social Sciences

Table 6 :Correlogram of Daily Stock Returns of Mexico

\begin{tabular}{|c|c|c|c|c|}
\hline Lag & $\mathrm{AC}$ & PAC & Q-Stat & Prob \\
\hline 1 & -0.004 & -0.004 & 0.0569 & 0.811 \\
\hline 2 & 0.084 & 0.084 & 22.488 & 0.000 \\
\hline 3 & 0.059 & 0.060 & 33.661 & 0.000 \\
\hline 4 & 0.093 & 0.088 & 61.095 & 0.000 \\
\hline 5 & 0.063 & 0.056 & 73.824 & 0.000 \\
\hline 6 & 0.095 & 0.081 & 102.52 & 0.000 \\
\hline 7 & 0.040 & 0.024 & 107.52 & 0.000 \\
\hline 8 & 0.053 & 0.028 & 116.59 & 0.000 \\
\hline 9 & 0.059 & 0.037 & 127.59 & 0.000 \\
\hline 10 & 0.088 & 0.065 & 152.22 & 0.000 \\
\hline 11 & 0.048 & 0.027 & 159.44 & 0.000 \\
\hline 12 & 0.059 & 0.030 & 170.39 & 0.000 \\
\hline 13 & 0.035 & 0.009 & 174.23 & 0.000 \\
\hline 14 & 0.065 & 0.034 & 187.62 & 0.000 \\
\hline 15 & 0.072 & 0.046 & 203.94 & 0.000 \\
\hline 16 & 0.034 & 0.004 & 207.57 & 0.000 \\
\hline 17 & 0.079 & 0.051 & 227.25 & 0.000 \\
\hline 18 & 0.051 & 0.025 & 235.58 & 0.000 \\
\hline 19 & 0.040 & 0.007 & 240.73 & 0.000 \\
\hline 20 & 0.060 & 0.026 & 252.19 & 0.000 \\
\hline 21 & 0.042 & 0.009 & 257.74 & 0.000 \\
\hline 22 & 0.021 & -0.011 & 259.16 & 0.000 \\
\hline 23 & 0.083 & 0.051 & 281.06 & 0.000 \\
\hline 24 & 0.019 & -0.009 & 282.17 & 0.000 \\
\hline 25 & 0.044 & 0.009 & 288.36 & 0.000 \\
\hline 26 & 0.036 & 0.008 & 292.44 & 0.000 \\
\hline 27 & 0.049 & 0.015 & 300.00 & 0.000 \\
\hline 28 & 0.064 & 0.040 & 312.90 & 0.000 \\
\hline 29 & 0.053 & 0.022 & 321.81 & 0.000 \\
\hline 30 & 0.030 & 0.001 & 324.64 & 0.000 \\
\hline 31 & 0.025 & -0.007 & 326.70 & 0.000 \\
\hline 32 & 0.051 & 0.017 & 334.92 & 0.000 \\
\hline 33 & 0.030 & -0.001 & 337.86 & 0.000 \\
\hline 34 & 0.033 & 0.002 & 341.30 & 0.000 \\
\hline 35 & 0.033 & 0.002 & 344.70 & 0.000 \\
\hline 36 & 0.016 & -0.009 & 345.50 & 0.000 \\
\hline
\end{tabular}


IRA-International Journal of Management \& Social Sciences

Table 7: Correlogram of Daily Stock Returns of Russia

\begin{tabular}{|c|c|c|c|c|}
\hline Lag & $\mathrm{AC}$ & PAC & Q-Stat & Prob \\
\hline 1 & 0.123 & 0.123 & 46.868 & 0.000 \\
\hline 2 & 0.171 & 0.158 & 136.26 & 0.000 \\
\hline 3 & 0.157 & 0.125 & 212.46 & 0.000 \\
\hline 4 & 0.113 & 0.063 & 251.45 & 0.000 \\
\hline 5 & 0.130 & 0.077 & 303.67 & 0.000 \\
\hline 6 & 0.099 & 0.042 & 333.74 & 0.000 \\
\hline 7 & 0.101 & 0.044 & 365.38 & 0.000 \\
\hline 8 & 0.116 & 0.059 & 406.48 & 0.000 \\
\hline 9 & 0.112 & 0.055 & 444.93 & 0.000 \\
\hline 10 & 0.098 & 0.034 & 474.23 & 0.000 \\
\hline 11 & 0.126 & 0.064 & 523.43 & 0.000 \\
\hline 12 & 0.098 & 0.031 & 553.26 & 0.000 \\
\hline 13 & 0.108 & 0.039 & 589.31 & 0.000 \\
\hline 14 & 0.105 & 0.035 & 623.64 & 0.000 \\
\hline 15 & 0.113 & 0.045 & 663.05 & 0.000 \\
\hline 16 & 0.083 & 0.008 & 684.23 & 0.000 \\
\hline 17 & 0.083 & 0.011 & 705.72 & 0.000 \\
\hline 18 & 0.096 & 0.028 & 734.34 & 0.000 \\
\hline 19 & 0.122 & 0.059 & 780.56 & 0.000 \\
\hline 20 & 0.091 & 0.018 & 806.07 & 0.000 \\
\hline 21 & 0.097 & 0.023 & 835.46 & 0.000 \\
\hline 22 & 0.091 & 0.015 & 861.27 & 0.000 \\
\hline 23 & 0.079 & 0.004 & 880.44 & 0.000 \\
\hline 24 & 0.088 & 0.016 & 904.67 & 0.000 \\
\hline 25 & 0.094 & 0.028 & 932.27 & 0.000 \\
\hline 26 & 0.095 & 0.026 & 960.43 & 0.000 \\
\hline 27 & 0.081 & 0.007 & 980.61 & 0.000 \\
\hline 28 & 0.073 & -0.001 & 997.02 & 0.000 \\
\hline 29 & 0.102 & 0.035 & 1029.5 & 0.000 \\
\hline 30 & 0.104 & 0.035 & 1062.9 & 0.000 \\
\hline 31 & 0.062 & -0.012 & 1074.9 & 0.000 \\
\hline 32 & 0.086 & 0.012 & 1097.9 & 0.000 \\
\hline 33 & 0.097 & 0.029 & 1127.1 & 0.000 \\
\hline 34 & 0.077 & 0.005 & 1145.6 & 0.000 \\
\hline 35 & 0.124 & 0.057 & 1193.2 & 0.000 \\
\hline 36 & 0.091 & 0.021 & 1219.2 & 0.000 \\
\hline
\end{tabular}


IRA-International Journal of Management \& Social Sciences

Table 8: Correlogram of Daily Stock Returns of Turkey

\begin{tabular}{|c|c|c|c|c|}
\hline Lag & $\mathrm{AC}$ & PAC & Q-Stat & Prob \\
\hline 1 & 0.143 & 0.143 & 66.699 & 0.000 \\
\hline 2 & 0.172 & 0.155 & 163.14 & 0.000 \\
\hline 3 & 0.170 & 0.133 & 257.53 & 0.000 \\
\hline 4 & 0.171 & 0.118 & 352.97 & 0.000 \\
\hline 5 & 0.137 & 0.068 & 413.66 & 0.000 \\
\hline 6 & 0.133 & 0.059 & 471.37 & 0.000 \\
\hline 7 & 0.161 & 0.088 & 555.51 & 0.000 \\
\hline 8 & 0.149 & 0.070 & 627.83 & 0.000 \\
\hline 9 & 0.143 & 0.059 & 694.79 & 0.000 \\
\hline 10 & 0.143 & 0.054 & 761.28 & 0.000 \\
\hline 11 & 0.129 & 0.035 & 815.73 & 0.000 \\
\hline 12 & 0.147 & 0.055 & 885.86 & 0.000 \\
\hline 13 & 0.149 & 0.058 & 958.60 & 0.000 \\
\hline 14 & 0.144 & 0.047 & 1026.1 & 0.000 \\
\hline 15 & 0.094 & -0.012 & 1054.7 & 0.000 \\
\hline 16 & 0.144 & 0.046 & 1122.5 & 0.000 \\
\hline 17 & 0.117 & 0.019 & 1167.6 & 0.000 \\
\hline 18 & 0.105 & 0.007 & 1203.6 & 0.000 \\
\hline 19 & 0.153 & 0.063 & 1279.9 & 0.000 \\
\hline 20 & 0.125 & 0.026 & 1331.0 & 0.000 \\
\hline 21 & 0.131 & 0.031 & 1387.1 & 0.000 \\
\hline 22 & 0.141 & 0.043 & 1451.7 & 0.000 \\
\hline 23 & 0.119 & 0.013 & 1498.0 & 0.000 \\
\hline 24 & 0.122 & 0.019 & 1546.5 & 0.000 \\
\hline 25 & 0.101 & -0.002 & 1580.2 & 0.000 \\
\hline 26 & 0.118 & 0.014 & 1625.5 & 0.000 \\
\hline 27 & 0.121 & 0.025 & 1673.5 & 0.000 \\
\hline 28 & 0.112 & 0.014 & 1714.8 & 0.000 \\
\hline 29 & 0.117 & 0.018 & 1759.6 & 0.000 \\
\hline 30 & 0.093 & -0.011 & 1787.7 & 0.000 \\
\hline 31 & 0.114 & 0.017 & 1830.0 & 0.000 \\
\hline 32 & 0.121 & 0.026 & 1877.8 & 0.000 \\
\hline 33 & 0.125 & 0.029 & 1929.3 & 0.000 \\
\hline 34 & 0.105 & 0.009 & 1965.4 & 0.000 \\
\hline 35 & 0.109 & 0.007 & 2004.5 & 0.000 \\
\hline 36 & 0.125 & 0.028 & 2055.5 & 0.000 \\
\hline
\end{tabular}


Table 9: Arch Test table

\begin{tabular}{|c|c|c|c|c|c|}
\hline \multirow{2}{*}{$\begin{array}{l}\text { Series } \\
\text { India } \\
\end{array}$} & \multicolumn{2}{|c|}{ H0: No arch effect } & \multicolumn{2}{|c|}{ Ho: Null hypothesis is rejected } & \multirow{2}{*}{ Arch effect present } \\
\hline & F-statistic & 1.391735 & Probability & 0.060774 & \\
\hline & Obs*R-squared & 49.89395 & Probability & 0.061690 & YES \\
\hline \multicolumn{6}{|l|}{ Brazil } \\
\hline & F-statistic & 0.762226 & Probability & 0.845575 & \\
\hline & Obs*R-squared & 27.52452 & Probability & 0.843709 & YES \\
\hline \multicolumn{6}{|l|}{ China } \\
\hline & F-statistic & 1.575734 & Probability & 0.015968 & \\
\hline & Obs*R-squared & 56.38197 & Probability & 0.016483 & NO \\
\hline \multicolumn{6}{|l|}{ Mexico } \\
\hline & F-statistic & 0.776179 & Probability & 0.828283 & \\
\hline & Obs*R-squared & 28.02348 & Probability & 0.826363 & YES \\
\hline \multicolumn{6}{|l|}{ Russia } \\
\hline & F-statistic & 1.040742 & Probability & 0.402646 & \\
\hline & Obs*R-squared & 37.46095 & Probability & 0.401948 & YES \\
\hline \multicolumn{6}{|l|}{ Turkey } \\
\hline & F-statistic & 0.667853 & Probability & 0.935484 & \\
\hline & Obs*R-squared & 24.14013 & Probability & 0.934309 & YES \\
\hline
\end{tabular}


Estimated GARCH Test for the Daily Returns of emerging equity market: Table 10

\begin{tabular}{|c|c|c|c|c|c|c|c|}
\hline S.NO. & Term & India & Brazil & China & Mexico & Russia & Turkey \\
\hline 1. & $\alpha_{1}$ & 0.061426 & $\begin{array}{c}- \\
0.008299\end{array}$ & -0.011776 & -0.008156 & 0.060167 & 0.023458 \\
\hline 2. & $\overline{\beta_{1}}$ & -0.160613 & $\begin{array}{c}- \\
0.965046\end{array}$ & -0.243629 & -0.965699 & 0.270912 & 0.895963 \\
\hline 3. & $\overline{\alpha_{1}+\beta_{1}}$ & -0.099187 & $\begin{array}{c}- \\
0.973345 \\
0\end{array}$ & -0.255405 & -0.973855 & 0.331079 & 0.919421 \\
\hline 4. & $\begin{array}{c}\text { Forecasted } \\
\text { return value }\end{array}$ & -0.331885 & $\begin{array}{c}- \\
0.111992\end{array}$ & -0.376700 & -0.114398 & -0.070990 & -0.474090 \\
\hline 5. & $\begin{array}{c}\text { Forecasted } \\
\text { variance }\end{array}$ & 0.999964 & 0.999982 & 0.999996 & 0.999983 & 0.999985 & 0.999883 \\
\hline 6. & $\begin{array}{l}\text { Akaike info } \\
\text { criterion }\end{array}$ & 2.917833 & 2.813982 & 2.958796 & 2.813605 & 2.897278 & 2.926092 \\
\hline 7. & $\begin{array}{l}\text { Schwarz } \\
\text { criterion }\end{array}$ & 2.925479 & 2.821663 & 2.966258 & 2.821257 & 2.905134 & 2.933589 \\
\hline 8. & $\begin{array}{c}\text { Durbin-Watson } \\
\text { static }\end{array}$ & 1.762341 & 2.011053 & 1.943094 & 2.008217 & 1.752708 & 1.711763 \\
\hline
\end{tabular}

Estimated E-GARCH Test for the Daily Returns of emerging equity market: Table 11

\begin{tabular}{|c|c|c|c|c|c|c|c|}
\hline Country & \multicolumn{3}{|c|}{ India } & \multicolumn{2}{|c|}{ Brazil } & \multicolumn{2}{|c|}{ China } \\
\hline S.NO. & Term & Coefficient & Prob. & Coefficient & Prob. & Coefficient & Prob. \\
\hline 1. & $\mathbf{C}$ & -16.71642 & 0.0000 & -11.93683 & 0.0741 & -3.420103 & 0.0000 \\
\hline 2. & $\mathrm{C}(2)$ & - & - & - & - & - & - \\
\hline 3 & $\mathrm{C}(3)$ & -0.004710 & 0.0001 & -0.003930 & 0.0777 & -0.011876 & 0.0228 \\
\hline 4 & $\mathrm{C}(4)$ & 0.010160 & 0.0000 & 0.006690 & 0.1167 & 0.024416 & 0.0016 \\
\hline 5. & $\mathrm{C}(5)$ & 0.008235 & 0.0000 & 0.006521 & 0.1021 & 0.029218 & 0.0000 \\
\hline & $\mathrm{C}(\mathbf{6})$ & 0.983554 & 0.0000 & 0.988408 & 0.0000 & 0.981185 & 0.0000 \\
\hline 6. & Forecasted return value & 16.72551 & & 11.12153 & & 0.401207 & \\
\hline 7. & Forecasted variance & 0.975578 & & 0.956798 & & 0.007650 & \\
\hline 8. & Akaike info criterion & 2.756647 & & 2.725080 & & 2.828416 & \\
\hline 9. & Schwarz criterion & 2.770032 & & 2.738525 & & 2.841478 & \\
\hline 10. & Durbin-Watson static & 1.935196 & & 2.098009 & & 2.089764 & \\
\hline
\end{tabular}


Table12: Estimated E-GARCH Test for the Daily Returns of emerging equity market continued

\begin{tabular}{|c|c|c|c|c|c|c|c|}
\hline \multirow{2}{*}{$\begin{array}{c}\text { Country } \\
\text { S.NO. }\end{array}$} & \multicolumn{3}{|c|}{ Mexico } & \multicolumn{2}{|c|}{ Russia } & \multicolumn{2}{|c|}{ Turkey } \\
\hline & Term & Coefficient & Prob. & Coefficient & Prob. & Coefficient & Prob. \\
\hline 1. & $\mathbf{C}$ & -15.27324 & 0.0135 & -21.55260 & 0.0003 & -3.316213 & 0.0000 \\
\hline 2. & $\mathrm{C}(2)$ & - & - & - & - & - & - \\
\hline 3. & $\mathrm{C}(3)$ & -0.003291 & 0.0236 & -0.001436 & 0.1858 & -0.029915 & 0.0001 \\
\hline 4. & $\mathrm{C}(4)$ & 0.005323 & 0.0414 & 0.005188 & 0.0057 & 0.056725 & 0.0000 \\
\hline 5. & $\mathbf{C}(5)$ & 0.005100 & 0.0273 & 0.006573 & 0.0014 & 0.067507 & 0.0000 \\
\hline & $\mathbf{C}(6)$ & 0.988030 & 0.0000 & 0.978679 & 0.0000 & 0.959816 & 0.0000 \\
\hline 6. & Forecasted return value & 19.54292 & & 22.1935 & & 0.331691 & \\
\hline 7. & Forecasted variance & 0.972284 & & 0.984470 & & 0.099476 & \\
\hline 8. & Akaike info criterion & 2.723795 & & 2.754658 & & 2.750740 & \\
\hline 9. & Schwarz criterion & 2.737191 & & 2.768406 & & 2.763862 & \\
\hline 10. & Durbin-Watson static & 2.096350 & & 1.999072 & & 1.935856 & \\
\hline
\end{tabular}

Estimated PARCH Test for the Daily Returns of emerging equity market: Table $\mathbf{1 3}$

\begin{tabular}{|c|c|c|c|c|c|c|c|}
\hline Country & \multicolumn{3}{|c|}{ India } & \multicolumn{2}{|c|}{ Brazil } & \multicolumn{2}{|c|}{ China } \\
\hline S.NO. & Term & Coefficient & Prob. & Coefficient & Prob. & Coefficient & Prob. \\
\hline 1. & $\mathbf{C}$ & -0.226889 & 0.0000 & -0.015339 & 0.3809 & -0.259605 & 0.0000 \\
\hline 2. & $\mathrm{C}(2)$ & 0.137711 & 0.0213 & 0.046805 & 0.0944 & 1.337595 & 0.0014 \\
\hline 3. & $\mathrm{C}(3)$ & -0.019604 & 0.0405 & -0.007916 & 0.1936 & -0.020384 & 0.4411 \\
\hline 4. & $\mathrm{C}(4)$ & 1.000000 & 0.0020 & 1.000000 & 0.2451 & 1.000000 & 0.6192 \\
\hline 5. & $\mathrm{C}(5)$ & 0.885196 & 0.0000 & 0.959577 & 0.0000 & -0.229351 & 0.5596 \\
\hline 6. & Forecasted return value & -0.22689 & & -0.01534 & & -0.25961 & \\
\hline 7. & Forecasted variance & 0.991108 & & 0.989694 & & 0.987564 & \\
\hline 8. & Akaike info criterion & 2.840213 & & 2.755011 & & 2.876881 & \\
\hline 9. & Schwarz criterion & 2.851686 & & 2.766535 & & 2.888077 & \\
\hline 10. & Durbin-Watson static & 1.747044 & & 1.991144 & & 1.919907 & \\
\hline
\end{tabular}


Table 14: Estimated PARCH Test for the Daily Returns of emerging equity market continued

\begin{tabular}{|c|c|c|c|c|c|c|c|}
\hline \multirow{2}{*}{$\begin{array}{c}\text { Country } \\
\text { S.NO. }\end{array}$} & \multicolumn{3}{|c|}{ Mexico } & \multicolumn{2}{|c|}{ Russia } & \multicolumn{2}{|c|}{ Turkey } \\
\hline & Term & Coefficient & Prob. & Coefficient & Prob. & Coefficient & Prob. \\
\hline 1. & $\mathbf{C}$ & -0.018877 & 0.2805 & 0.016270 & 0.3668 & -0.367032 & 0.0000 \\
\hline 2. & $\mathrm{C}(2)$ & 0.046148 & 0.0937 & 0.190905 & 0.0419 & 0.140696 & 0.0408 \\
\hline 3 & $\mathrm{C}(3)$ & -0.007868 & 0.1921 & 0.060222 & 0.0109 & -0.008191 & 0.3754 \\
\hline 4 & $\mathrm{C}(4)$ & 1.000000 & 0.2411 & -0.499221 & 0.0018 & 1.000000 & 0.4424 \\
\hline 5. & $\mathrm{C}(5)$ & 0.960162 & 0.0000 & 0.774534 & 0.0000 & 0.873334 & 0.0000 \\
\hline 6. & Forecasted return value & -0.01888 & & 0.01627 & & -0.36703 & \\
\hline 7. & Forecasted variance & 0.989922 & & 0.993521 & & 0.991799 & \\
\hline 8. & Akaike info criterion & 2.755410 & & 2.827485 & & 2.857936 & \\
\hline 9. & Schwarz criterion & 2.766892 & & 2.839269 & & 2.869184 & \\
\hline 10. & Durbin-Watson static & 1.987600 & & 1.741379 & & 1.695529 & \\
\hline
\end{tabular}

Table 15: COMPARISION OF BEST FIT MODEL

\begin{tabular}{|c|c|c|c|c|c|c|}
\hline & India & Brazil & China & Mexico & Russia & Turkey \\
\hline \multicolumn{7}{|l|}{ Garch } \\
\hline $\begin{array}{l}\text { Akaike info } \\
\text { criterion }\end{array}$ & 2.917833 & 2.813982 & 2.958796 & 2.813605 & 2.897278 & 2.926092 \\
\hline $\begin{array}{l}\text { Schwarz } \\
\text { criterion }\end{array}$ & 2.925479 & 2.821663 & 2.966258 & 2.821257 & 2.905134 & 2.933589 \\
\hline \multicolumn{7}{|l|}{ EGARCH } \\
\hline $\begin{array}{l}\text { Akaike info } \\
\text { criterion }\end{array}$ & 2.756647 & 2.725080 & 2.828416 & 2.723795 & 2.754658 & 2.750740 \\
\hline $\begin{array}{l}\text { Schwarz } \\
\text { criterion }\end{array}$ & 2.770032 & 2.738525 & 2.841478 & 2.737191 & 2.768406 & 2.763862 \\
\hline \multicolumn{7}{|l|}{ PARCH } \\
\hline $\begin{array}{l}\text { Akaike info } \\
\text { criterion }\end{array}$ & 2.840213 & 2.755011 & 2.876881 & 2.755410 & 2.827485 & 2.857936 \\
\hline $\begin{array}{l}\text { Schwarz } \\
\text { criterion }\end{array}$ & 2.851686 & 2.766535 & 2.888077 & 2.766892 & 2.839269 & 2.869184 \\
\hline
\end{tabular}


IRA-International Journal of Management \& Social Sciences

Table 16: Calculation of VaR

\begin{tabular}{|l|l|}
\hline Country & VaR value at 95 \% significant level \\
\hline India & -2022089.793 \\
\hline Brazil & -2039133.464 \\
\hline China & -1988134.686 \\
\hline Mexico & -2022089.793 \\
\hline Russia & -2043939.735 \\
\hline Turkey & -1996832.785 \\
\hline
\end{tabular}

